\title{
The Influence of Self-Esteem and Peer Pressure on Career Choice of Adolescents in Greater Accra, Ghana
}

\author{
Peter Worlanyo Abomah ${ }^{1 *}$, Amanda Naa Ayorkor Tagoe ${ }^{1}$ \\ ${ }^{1}$ Department of Social Sciences, Methodist University College Ghana, Dansoman Accra, \\ Ghana
}

\begin{abstract}
The study examined the influence of self-esteem and Peer pressure on the career choice of adolescents. The purpose was to determine the relationship between Peer pressure and career choice, the relationship between self-esteem and career choice, and compare the influence of self-esteem and Peer pressure on adolescent boys and girls. Cross-sectional and descriptive was the research design. Cluster sampling was used to select four schools, and stratified proportional, and simple random sampling was used to select 200 respondents. Rosenberg self-esteem, Peer pressure, and career decision scales were used to collect data from 200 Senior High School students in selected schools in the Greater Accra region Ghana. Pearson's correlation and regression analysis were the statistical tools for the analysis of data. The results indicate that self-esteem positively correlates with the career choice of adolescents. Peer pressure positively correlates career choices of adolescents. There is no gender differences in Peer pressure and career choice of adolescents. Challenges of career choice among adolescents include the lack of career guidance, the influence of family, general indecisiveness, the desire to pursue a career that earns much, and the opinion of their peer concerning career choice.
\end{abstract}

Keywords: Adolescence, Career Choice, Peer pressure, self-esteem.

\section{Introduction}

The study investigated the influence of selfesteem and peer pressure on career choice of adolescents in Greater Accra Ghana. At a certain stage in everyone's life, we all must choose a career path to pursue. In the case of children, they often have different dreams and interests they desire to pursue in life. However, as they all grow into adolescents, the choice of a career path becomes an important decision staring us in the face. Career decision-making is even more crucial for adolescents, as they may not have enough information to make an informed decision that will be suitable for their talents, abilities, and personality.

Preparation for a career during the adolescence period "is an important precursor for successful career development across the life span and is closely related to adolescence adjustment and well-being. Since adolescence is a universal phenomenon, so is career choice. According to [1] in America, 20\% - 60\% of new students joining institutions of higher learning are usually undecided over their supposed career choices". Studies conducted by some researchers in assessing the individual factors causing difficulties in career decisionmaking far revealed the value of self-esteem among other variables [2].

This is to affirm that self-esteem and other variables such as peer pressure play a role in adolescents' career choice. According to [3] self-esteem has a long, prolific history on psychology. The issue of peer pressure on career choice is no exception to this phenomenon. 
A recent study in Kenya found out that there was a significant influence of peer pressure on career decision-making among students [1]. Current research in Ghana has mostly focused on processes related to youths not choosing appropriate career hence the high unemployment rate. Studies conducted have not focused on causal factors of poor career decisions. This study is to fill the gap. The aim is to determine the relationship between selfesteem on adolescent and their career choice in the Ghanaian context and to determine the influence of peer pressure and self-esteem on the career choice of adolescents.

The main purpose of this was to find out if self-esteem and peer pressure will have a significant influence on adolescents' career choices. It is also to examine the level of selfesteem and peer pressure that can influence career decision-making or choice among adolescents. The objectives of the study include describing the influence of self-esteem and peer pressure on the career choice of adolescents, determining the relationship that exists between peer pressure and career choice of adolescents, determining the relationship that exists between self-esteem and career choice of adolescents, to identify the challenges of career choice among adolescents and to compare gender influence of self-esteem and peer-pressure on adolescents. The paper is organized as follows, an introduction which includes (problem statement and purpose of study), and brief empirical studies.

Then, the highlight of the method used in this study, result, and discussion of the findings and recommendations. In the work of [4] on self-esteem revealed that self-esteem affected the career prospects of males. The story was not much different for females as the study revealed that self-esteem influenced their career expectations and directly affected their career planning and exploration [5]. it is studied "the Relationships of Self-Esteem, Future Time Perspective, Positive Affect, Social Support, and Career Decision". They postulated that self- esteem was related positively to career decision-making self-efficacy and negatively to career choice anxiety. Career according to [6] [15], is the application of a person's cognition and capabilities, providing command over the profession, timely work expertise, and a basis of developing and bettering business networks. According to [5], the study revealed that "individuals with a high self-esteem are more likely to choose challenging goals than those with low self-esteem".

Since career choices are goals in themselves, this study indicates that high self-esteem affects career choice. According to [1], who conducted research on the effectiveness of Peer Pressure on Students' Career Decision Making in Secondary Schools in Kenya and found out that there was a significant influence of peer pressure on career decision-making among students. In the research of [7], [19], who studied the factors affecting students' career choice, they reported that girls are more inclined towards their peers, and their choices are dependent on them.

According to [8], their review of other literature indicates that three main areas that influence the adolescent choice of career. These factors are environment, opportunity, and personality, in addition to self-esteem and Peer pressure. The influence of self-esteem and Peer pressure should be investigated in addition to environmental opportunity and personality to clearly identify compelling factors that influence the career choice of adolescents hence the study.

\section{Methodology}

The study was conducted using mixed research and descriptive design. Data was collected from 200 SHS students selected from the target population of 1,500 students in four districts in Greater Accra, Ghana. Cluster sampling was used to select 4 out 8 schools put in 4clusters. Stractified proportional was used to male and female students. Simple random was used to select respondents. A list of 8 
schools was put in four clusters, and a simple random was used to select one school from each cluster. Standardized questionaire including Rosenberg self-esteem scale, Peer pressure inventory scale and career decision scale were used to collect data. Ethical issues like permission sought from parents of respondents below 18 years. Data obtained from the respondent was used only for the research purpose. Data collected using questionnaires were analyzed using the Statistical Package for Social Sciences (SPSS) version 16.0. Internal consistency for the Rosenberg Self-esteem scale ranges from 0.77 to 0.88 . Test re-test reliability for the Rosenberg Self-esteem scale ranges from 0.82 to 0.85 . With respect to measuring adolescents peer pressure, the Peer Pressure inventory scale, which was developed by Bradford Brown and Donna Rae Clasen in 1985 was used.
According to Weist [10], "the overall reliability of the Peer Pressure Inventory is $\alpha=.93$ which demonstrates a good reliability". Career Choice: The [11] Career Decision Scale was used to measure the career choice of adolescent students in the study. After permission was obtained, the researchers put the students into two groups (boys and girls) and sampled them. After simple random sampling, the researchers put the selected students in one class and administered the questionnaires to the respondents who gave their consent to participate in the study. The students were given specific guidelines regarding how the questionnaire should be filled in and allowed to ask questions for clarification if they did not understand anything. Ethical rules were not violated, and issues like confidentiality, annonimity were strictly adhered to.

\section{Results}

Table 1. Demographic Variables of Respondents

\begin{tabular}{|l|l|l|}
\hline Variables & Frequency & Percentage \\
\hline Gender & 100 & 50.0 \\
\hline Male & 100 & 50.0 \\
\hline female & \multicolumn{2}{|l|}{} \\
\hline Age & 5 & 2.5 \\
\hline $12-13$ years & 102 & 51.0 \\
\hline $14-15$ years & 93 & 46.5 \\
\hline $16-17$ years & \multicolumn{2}{|l|}{} \\
\hline Educational level & 200 & 100.0 \\
\hline JHS 1 & \multicolumn{3}{|l|}{} \\
\hline Courses being studied in the SHS \\
\hline Agric Science & 1 & 0.5 \\
\hline Business & 33 & 16.5 \\
\hline General Arts & 87 & 43.5 \\
\hline General Science & 26 & 13.0 \\
\hline Home Economics & 8 & 4.0 \\
\hline Science & 29 & 14.5 \\
\hline Visual Arts & 16 & 8.0 \\
\hline
\end{tabular}

Table 1 presents the fair distribution of gender as data was collected from an equal number of males and females. Hence, males represented $50 \%$ of respondents, and females as well represented $50 \%$ of respondents. In terms of gender, more than half of respondents were 
within the age range of 14-15 years. In addition, 93 respondents representing $46.5 \%$ of respondents, were within the age bracket of 1617. Those in the minority (5 respondents), representing $2.5 \%$ of respondents, were between the ages of 12-13 years. As indicated in Table 1, data was collected from SHS1 students; the level of education for all 200 respondents was SHS1. Data on respondents' course of study at the SHS 1 level shows that
$43.5 \%$ of all respondents were General Arts students. This was followed by science students who made up $27.5 \%$ of all respondents. Business students involved in the study constituted $16.5 \%$ of respondents. Visual Arts students represented $8 \%$ of respondents. Home Economics and Agriculture Science students were in the minority, representing $4 \%$ and $0.5 \%$ of respondents, respectively.

Table 2. Summary of Pearson Correlation between Self-esteem and Career choice

\begin{tabular}{|l|l|l|}
\hline Variables & Career choice & Peer pressure \\
\hline Career Choice & 1 & \\
\hline Self-esteem & 0.2262 & 1 \\
\hline
\end{tabular}

[Source: Field data (2019)] *p is significant @ .05 alpha levels

As can be seen from Table 2 at a correlation coefficient of $\mathrm{r}=0.23$ (2d.p.) approximately, there exists a positively weak relationship (correlation) between self-esteem and career choice of the adolescents. Hence, the first hypothesis self-esteem has an influence on the career choice of adolescents is significant. Therefore, we fail to reject Hypothesis 1.

Table 3. Summary of Correlation between peer pressure and career choice

\begin{tabular}{|l|l|l|}
\hline Variables & Career choice & Peer pressure \\
\hline Career Choice & 1 & \\
\hline Peer Pressure & 0.1387 & 1 \\
\hline
\end{tabular}

[Source: Field data (2019)]*p is significant @ .05 alpha levels

At a correlation coefficient of $r=0.14$ (2d.p.), as evident in Table 3, it could be said that there is a positive relationship between the career choice of adolescents and their peer pressure. Therefore, it can be said that peer pressure has some influence on the career choice of adolescents. We fail to reject hypothesis 3 .

Table 4. Multiple Regression Results for Career Choice on Self-esteem and Peer Pressure

\begin{tabular}{|l|l|l|l|l|l|l|}
\hline Career Choice & Coef. & Std. Err. & T & P>t & [95\% Conf. & Interval] \\
\hline Self-esteem & 0.2334153 & 0.078715 & 2.97 & 0.003 & 0.0781826 & 0.38865 \\
\hline Peer pressure & 0.1060162 & 0.07323 & 1.45 & 0.149 & -0.0383986 & 0.25043 \\
\hline Constant & 1.672256 & 0.244019 & 6.85 & 0 & 1.191031 & 2.15348 \\
\hline R -squared & 0.0611 & & & & & \\
\hline Adj. R-squared & 0.0516 & & & & & \\
\hline Root MSE & 0.6064 & & & & & \\
\hline F(1, 198) & 6.42 & & & & & \\
\hline Prob> F & 0.002 & & & & & \\
\hline
\end{tabular}

[Source: Field data (2019)] *p is significant @ .05 alpha levels

Table 4 depicts that the regression model is statistically significant, $F(2,197)=6.42$ and $p$ $=0.002$. Since the F-statistic $(p=0.002)$ is less than 0.5 degree of freedom at a $95 \%$ confidence interval, the model is, therefore, considered valid and fit to test the statistical significance of 
the influence that both self-esteem and peer pressure respectively have on career choice of adolescents. Again, the Adjusted R-Squared of 0.0611 shown in Table 4 explains the respective percentage of self-esteem and peer pressure that results in the career choice of adolescents. It thus, indicates that both self-esteem and peer pressure explain $6.11 \%$ variability in career choices of the population of the adolescents studied. Further, the result of regression analysis in Table 4 depicts a regression coefficient of 0.2334153 for a p-value of 0.003 at a confidence interval of 0.0781826 and 0.388648 with respect to the influence or effect of self-esteem on career choice. It also indicates 0.1060162 as the regression coefficient for a pvalue of 0.149 at the confidence interval of -
0.0383986 and 0.250431 with respect to the effect of peer pressure on career choice. The regression results here explain that both selfesteem and peer pressure positively influence career aspirations of the 200 adolescents studied. It describes that a percentage $(1.00 \%)$ change in career choice decision or preference of the adolescents could be approximately explained by $23.34 \%$ and $10.60 \%$ changes in both self-esteem and peer pressure of the adolescents, respectively. Since this occurs at a $\mathrm{p}$-value less than 0.05 , the influence of these two predictive variables on career choice is deemed significant. The findings indicate that there is a statistically significant influence of self-esteem and peer pressure on the career choice of adolescents.

Table 5. Regression Analysis of Peer Pressure on Gender of Adolescents

\begin{tabular}{|l|l|l|l|l|l|l|}
\hline Variables & \multicolumn{5}{|l|}{ Peer Pressure } \\
\hline Gender & Coefficient & Std. Error & $\mathbf{t}$ & $\mathbf{p}>[\mathbf{t}]$ & {$[\mathbf{9 5 \%}$ Conf. } & Interval] \\
\hline Female & 0.020336 & 0.08457 & -0.24 & 0.81 & -0.1871 & 0.146442 \\
\hline Constant & 2.413591 & 0.0598 & 40.36 & 0 & 2.29566 & 2.531521 \\
\hline R -squared & 0.0003 & & & & & \\
\hline Adj R-squared & -0.0048 & & & & & \\
\hline Root MSE & 0.59802 & & & & & \\
\hline F(1, 198) & 0.06 & & & & & \\
\hline Prob> F & 0.8102 & & & & & \\
\hline
\end{tabular}

From Table 5, it can be seen that $\mathrm{F}(1,198)=$ $0.06, p=0.8102$ for peer pressure and gender. Since the F-statistic $(\mathrm{p}=0.8102)$ is greater than 0.05 degree of freedom at $95 \%$ confidence interval, the model, therefore, could not be regarded as statistically significant to test the influence that peer pressure has on gender. If the lack of the model's statistical fitness is anything to be withheld; then, an Adjusted RSquared of -0.0048 shown in Table 5 could only explain that there is $-0.048 \%$ variability in career choices. The test for model fitness shows that $\mathrm{F}$ statistics $(1,198)$ is $0.06, \mathrm{~F}$ probability (which represents the $\mathrm{p}$-value for the regression model) is 0.81 and $\mathrm{R}$ squared is 0.0003 . Since the $\mathrm{p}$-value is greater than 0.05 , it could be said that the regression model lacks the fitness to test the significance of the relationship between peer pressure and gender. The regression table also shows that there is no significant relationship between peer pressure and gender.

Table 6. Regression Results Self-esteem on Gender of Adolescents

\begin{tabular}{|c|c|c|c|c|c|c|}
\hline Variables & \multicolumn{6}{|l|}{ Self-Esteem } \\
\hline Gender & Coefficient & Std. Error & $\mathbf{t}$ & $p>[t]$ & [95\% Conf. & Interval] \\
\hline Female & 0.3185555 & 0.07536 & 4.23 & 0 & 0.169938 & 0.467173 \\
\hline Constant & 2.355 & 0.05329 & 44.19 & 0 & 2.249911 & 2.460089 \\
\hline $\mathrm{R}$-squared & 0.0828 & & & & & \\
\hline
\end{tabular}




\begin{tabular}{|l|l|l|l|l|l|l|}
\hline Adj R-squared & 0.0781 & & & & & \\
\hline Root MSE & 0.5329 & & & & & \\
\hline F $(1,198)$ & 17.87 & & & & & \\
\hline Prob> F & 0 & & & & & \\
\hline
\end{tabular}

[Source: Field data (2019)] *p is significant @ .05 alpha levels

From Table 6, it can be seen that results for the model fitness shows that $F(1,198)$ is 17.87 , F probability is 0.000 , and $\mathrm{R}$-squared is 0.0828 . Since the p-value (F-probability) is less than 0.05 , it could be said that the model is fit enough to test the relationship between selfesteem and gender of adolescents. Furthermore, the coefficient of 0.318555 in the regression results shows that for each unit increase in gender, self-esteem increases by 0.318 points in females than in males, and the difference is statistically significant at a $95 \%$ confidence level. The R-squared value shows that $8.3 \%$ (0.0828) of the variation in self-esteem is explained by gender being female.

Additional Findings: The researcher also examined the relationship that exists between peer pressure and career choice as well as selfesteem and career choice using correlation analysis. The results are presented in table 7 and 8 .

Table 7. Correlation Result for Relationship between Peer Pressure and Career Choice

\begin{tabular}{|l|l|l|}
\hline Variables & Career choice & Peer pressure \\
\hline Career choice & 1 & \\
\hline Peer pressure & 0.1387 & 1 \\
\hline
\end{tabular}

[Source: Field data (2019)] *p is significant @ .05 alpha levels

At a correlation coefficient of $\mathrm{r}=0.14$ (2d.p.) as evident in Table 7, it could be said that there is a weak but positive relationship between the career choice of adolescents and their peer pressure.

Table 8. Correlation Result on Relationship between Self-esteem and Career Choice

\begin{tabular}{|l|l|l|}
\hline Variables & Career choice & self-esteem \\
\hline Career Choice & 1 & \\
\hline Self-esteem & 0.2262 & 1 \\
\hline
\end{tabular}

[Source: Field data (2019)] *p is significant @ .05 alpha levels

At a correlation coefficient of $\mathrm{r}=0.23$ (2d.p.) approximately, it was found that there exists a positively weak relationship (correlation) between self-esteem and career choice of the adolescents. Finally, the researcher used the qualitative method to find out the challenges faced by adolescents in making career choices at the SHS level. Content analysis was used to analyse the data. Results from analysis are Table 9.

Table 9. Challenges of Career Choice among Adolescents

\begin{tabular}{|l|l|l|}
\hline Challenges & Frequency & Percentage \\
\hline Fear of failure & 7 & 3.5 \\
\hline Lack of confidence & 9 & 4.5 \\
\hline Influence of family & 90 & 45 \\
\hline Lack of sufficient information about occupations & 35 & 17.5 \\
\hline General indecisiveness & 67 & 33.5 \\
\hline
\end{tabular}




\begin{tabular}{|l|l|l|}
\hline Lack of motivation & 41 & 20.5 \\
\hline Lack of proper career guidance & 98 & 49 \\
\hline Inability to identify talent & 13 & 6.5 \\
\hline Desire to pursue a career that earns much & 65 & 32.5 \\
\hline Ability of family to afford cost of training for the career & 15 & 7.5 \\
\hline Lack of role models in the family with career choice of student & 36 & 18 \\
\hline Peer's opinion of some career choices & 54 & 27 \\
\hline Inconsistent information about careers & 18 & 9 \\
\hline Internal conflict & 14 & 7 \\
\hline
\end{tabular}

[Source: Field data (2019)]

From the Table 9, it can be seen that adolescents face numerous challenges in making career decisions.

\section{Discussion}

The first hypothesis of the study was that "Self-esteem has a correlation with the career choice of adolescents. The findings of this study is consistent with the findings of [4], which revealed that self-esteem was not much different for females as their self-esteem influenced their career expectations and directly affected their career planning and exploration [5].

However, this study further explains that females were more influenced by their selfesteem in making a career choice than their male counterparts. Proponents of Donald Super's Career Model are of the view that "at every development stage, people encounter different experiences and as such their career choice was influenced by these experiences at varied stages" [14]. The theorist also believes that as self-concept keeps changing, a person's career choice will also keep changing as they go through the different stages in life. This theory, therefore, supports the findings of the study, which states that self-esteem has an influence on the career choice of adolescents [15]. Hence, the first hypothesis of the study has been supported since self-esteem positively influenced the career aspirations of adolescents.

The second hypothesis states that "Peer pressure has a correlation with the career choice of adolescents". The result, therefore, revealed that there is a significant positive relationship between peer pressure and career choice. The findings of this study are also consistent with the findings of [1], who conducted research on the "effectiveness of Peer Pressure on Student' Career Decision Making in Secondary Schools in Kenya and found out that there was a significant influence of peer pressure on career decision making among students".

The third hypothesis Self-esteem and peer pressure have no influence on the career choice of adolescents". From the results, there is a weak but positive relationship between the career choice of adolescents and their peer pressure. Since the regression analysis shows that there is no significant relationship between peer pressure and gender and the correlation analysis revealed that there is a weak but positive relationship between the career choice of adolescents and their peer pressure, the hypothesis was rejected. The findings of [7], who studied the factors affecting students' career choice, are not consistent with the findings of this study. The findings of [7] found out "that girls are more inclined towards their peers, and their choices are dependent on them". Hence, peer pressure affects the career choice of adolescent girls. Findings in relation to challenges of career choice among adolescents indicate that adolescents face many challenges in making a career choice. Hence the recommendation of [16], [19]. Key challenges include the lack of career guidance, the influence of family, general indecisiveness, the desire to pursue a career that earns much, the 
opinion of their peer's concerning their career choice, lack of motivation, lack of role models in the family with career choice of student, inconsistent information about careers, lack of sufficient information about occupations, the ability of adolescents' family to afford the cost of training for a chosen career among others. The gap has been filled that self-esteem and Peer pressure influence the career choice of adolescents.

\section{Conflict of Interest}

The researcher's interaction with adolescents during counselling sessions and what adolescents normally say influence the choice of variables self-esteem and peer influence on career choice. Though a number of studies exist on adolescent career choice, most of them focused on finding the factors that affect the career choice of adolescence and not how the career choice of adolescence is influenced by peer pressure and self-esteem. The reseacher's decided to investigate this area as a means to develop strategies for career facilitative counseling of adolescents in senior high Schools given the high rate of youth unemployment in Ghana. Research works

\section{References}

[1] Ogutu, J. J. P., Odera, P. \&Maragia, S. N. (2017). The Effectiveness of Peer Pressure on Student' Career Decision Making in Secondary School in Kenya. International Journal of Humanities and Social Studies, III (3), 16-32.

[2] Kounenou, K. 2012). Self-esteem, work values and career choice among Greek students of Higher pedagogical \& technological studies. Handbook of Psychology of Self-Esteem. Nova Publications, pp. 383-391.

[3] Abdel-Khalek, A. M. (2016). Introduction to Psychology of Self-Esteem. Research Gate, 1-23.

[4] Patton, W., Bartrum, D., \& Creed, P. (2004). Gender differences for optimism, self-esteem, expectations, and goals in predicting career planning and exploration in adolescents. International available that focused on gender in relation to career choice also mainly concerned itself with why adolescents who were males or females preferred some particular courses of study, for instance, science, mathematics, and arts that make it difficult to review data on the study, however, the research was able to obtain relevant literature for the study. Beyond selfesteem and Peer pressure, there may be other factors that could influence the career choice of adolescents worth researching into.

\section{Conclusions}

Findings in relation to challenges of career choice among adolescents show that the lack of career guidance, the influence of family, general indecisiveness, the desire to pursue a career that earns much, low self-esteem, and peer pressure were some of the challenges experienced by adolescents.

\section{Acknowledgement}

Appreciation to Amanda Naa Ayorkor Tagoe who collected data from the field and assisted in the conduct of the study as well as respondents who provided data for the study.

Journal for Educational and Vocational Guidance, 4(3), 193-209.

[5] Javed, Z., \& Tariq, O. (2016). Career-decisions, Self-efficacy, and Self-esteem among Students of Private and Government Academic Institutions. Pakistan Journal of Social and Clinical Psychology, 14(2), 42-46.

[6] Redman, T. \& Wilknson, A. 2001). Contemporary Human Resource Management, New York: Financial Times Prentice Hall.

[7] Kazi, A. S., \& Akhlaq, A. (2017). Factors Affecting Students' Career Choice. Journal of Research and Reflections in Education, 2, 187-196.

[8] Farreo, D. \& Garkuwa, J. 2018). Factors Influencing the Career Choice of Senior Secondary School Students in Hong local Government Area of 
Adamawa State, Nigeria. International Journal of Current Aspects in Social Sciences, 2 \{2\}, 1-9.

[9] Rosenberg, M 1965). Society and the Adolescent Self-Image. Research Gate. Retrieved November 4, 2018, from

https://www/researchgate.net/publication/20000890 0and-The-Adolescent-Self-Image.

[10] Weist, F. (2018). The Moderating Effect of the Social Norms on the Relationship between Stress and Cognitive-Enhancement Drug Use. Bachelor Thesis, University of Twente, Nertherlands. Retrieved August 1, 2019, from https://essay.utwente.nl/75219/1/Weist_BA_BMS.p df.

[11]Brown, J. D., Dutton, K. A. \& Cook, K. E. 2001). From the top down: Self-esteem and selfevaluation. Cognitive and Emotion, 15, 615-631.

[12] Osipow, S. H. Carney, C. G. \& Barak, A. 1976. A scale of educational-vocational undecidedness: A typological approach. Journal of Vocational Behavior, $\quad\{9\} 2, \quad 233-243$ https://doi.org/10/1016/0001-8791)\{76\}90081-6.

[13] Guay, F. Ratelle, C. F. Senecal, C. arose, S. \& Daschenes A. $\quad\{2006\}$. Distinguishing Developmental from Chronic Cancer Indecision: Self-Efficacy, Autonomy, and Social Support. Journal of Career Assessment 14 \{2\} 235-251.

[14]Dokosi, E. D. (2014). Investigating the factors influencing career choice amongst prospective and recent graduates in Ghana. (Undergraduate thesis, Ashesi University Ghana).
[15]Gati, I. \& Saka, N. \{2001\}. High School Students' Career-related decision-making difficulties. Journal of Counselling \& Development, 79 3), 331-340.

[16] Ghana Schools Net Senior High School-Greater Accra Region. Retrieved June 14, 2019, From https://www.ghanaschoolsnetcom/page/senior-highschool-greater?page $=2$.

[17] International Labourr Oganisation 2011. Global Employment Trends 2011: The Challenge of a Job recovery, International Labour Office, 1-51.

[18] Murphy, J. 2015. Schools should take the issue of Career Guidance for Students Seriously. Retrieved March 7, 2019, from http://www.Nation.co.ke/lifestyle/weekend/careerguidance-for-students-seriously/1220-2652758vhx4h3z/index.htm.

[19]Mize 2005.Relationship of career decisionmaking and self-esteem for college students and Athletes. Retrieved October 10, 2018, from: https://digitalcommons.georgiasouthern.edu/Egi/vie wcontent.egi?article $=1079 \&$ content $=$ etc .

[20] Moulton, S. 2019. Theories of Self-esteem: Early and modern. Retrieved March 20, 2019, from https://study.com/academy/lesson/theories-of-selfesteem-early-modern.html.

[21] Talib, J., Mahammed, Z. \& Mamat, M. [2011]. Effects of parenting style on children development. World Journal of Social Sciences, 1, 14-35. 